\title{
South African health practitioners' patterns of CPD practices - implications for maintenance of licensure
}

\author{
S A Singh, ${ }^{1} \mathrm{PhD} ; \mathrm{T}$ D Fish, ${ }^{2} \mathrm{MB} \mathrm{ChB}, \mathrm{MBA}$ \\ ${ }^{1}$ Department of Health and Rehabilitation Sciences, Faculty of Health Sciences, University of Cape Town, South Africa \\ ${ }^{2}$ Division of Health Systems and Public Health, Faculty of Medicine and Health Sciences, Stellenbosch University, Cape Town, South Africa
}

Corresponding author: S A Singh (shajila.singh@uct.ac.za)

\begin{abstract}
Background. The statutory requirement for continuing professional development (CPD) for all health professionals registered with the Health Professions Council of South Africa (HPCSA) has been in place since 2007. The HPCSA intends to implement maintenance of licensure (MoL).

Objectives. To determine practitioners' perceptions and experiences of engaging with CPD to inform the development of the MoL system.

Methods. A cross-sectional survey of practitioners registered with the HPCSA was conducted. The self-administered 30-item electronic questionnaire covered practitioner demographics and patterns of CPD practice and was completed by 11307 respondents.

Results. Methods used to determine learning needs included self-assessment (56.8\%) and audit of own practice (53.2\%). Selection of CPD activities was based on interest $(80.2 \%)$ and expertise $(72.8 \%)$ and less so on gaps in knowledge (66.1\%) and skills (61.8\%). The most frequent learning activities were primarily didactic (workshops (58\%), lectures (53\%) and conferences (51\%)). Barriers included cost and location of CPD activities, especially for women and rural practitioners $(p<0.001)$. Employer support for CPD was associated with adherence $(p<0.001)$. There was strong support $(88.7 \%)$ for continuing education as a component of MoL, but less support $(<50 \%)$ for other elements, even though practitioners voluntarily engaged with these practices.

Conclusion. Respondents engage in a range of activities that could be incorporated into a MoL system. The transition to MoL requires development of tools, including objective assessments, guidelines for individualised learning programmes and expanding the range of learning activities. Strategies to address barriers to CPD need to be considered.
\end{abstract}

Afr J Health Professions Educ 2019;11(4):123-128. https://doi.org/10.7196/AJHPE.2019.v11i4.1088

South Africa (SA) was one of the first countries to integrate 12 statutory health professional boards: Dental Therapy and Oral Hygiene (DOH); Dietetics and Nutrition (DTB); Emergency Care (EMB); Environmental Health (EHO); Medical and Dental (MDB); Medical Technology (MTB); Occupational Therapy, Medical Orthotics Prosthetics and Arts Therapy (OCT); Optometry and Dispensing Opticians (ODO); Physiotherapy, Podiatry and Biokinetics (PPB); Psychology (PSB); Radiography and Clinical Technology (RCT); Speech, Language and Hearing (SLH). These boards represent 83 professional categories under one umbrella body, the Health Professions Council of South Africa (HPCSA). In 2007, the HPCSA changed the statutory requirement to include continuing professional development (CPD) compliance to remain registered as a health practitioner. ${ }^{[1,2]}$ The intention was to promote ethical and competent practice, which requires continually updating knowledge and skills with an end benefit to the patient/client. ${ }^{[3]}$

The CPD system is one of self-selected continuing education activities to update knowledge and skills. Practitioners are required to engage with CPD for at least 30 hours per year (15 hours for certain categories), of which 5 hours must be in the area of ethics, human rights and health law. One hour is equivalent to one continuing education unit (CEU). The range of accredited learning activities includes those at level 1, i.e. once-off activities (e.g. workshops, lectures, seminars, conferences); and level 2, i.e. formal courses/programmes of study with measurable outcomes, and other activities (e.g. learning portfolios and practice audits). ${ }^{[3]}$ Practitioners are free to select learning activities and are expected to maintain their records. Random audits of practitioners, which require submission of CPD records, are conducted to determine adherence with the requirements.
A challenge for the HPCSA is its ability to assess the impact of CPD on practitioners' competence and performance ${ }^{[4]}$ to assure the public that practitioners are up to date with new knowledge, skills and current trends. Internationally, efforts to assess competence and performance, improve quality of care, detect early performance that does not meet the standard and promote professional accountability have seen the introduction of recertification, ${ }^{[5]}$ revalidation ${ }^{[6]}$ and maintenance of licensure $(\mathrm{MoL}){ }^{[7]}$ These processes require practitioners to improve practice by implementing an individualised CPD programme that meets the individual's learning needs, with assessment of performance and/or competence. ${ }^{[6,8]}$

In 2013, the HPCSA initiated the process for MoL. The rationale was to move beyond the acquisition of knowledge to include the development of skills and improvement of performance. Development of the MoL strategy is underway. This study set out to determine practitioners' perceptions and experiences relating to their engagement with $\mathrm{CPD}$ to inform the development of the MoL system.

\section{Methods}

A cross-sectional prospective survey design was used. Participants were required to be health practitioners registered with the HPCSA, and to have email access. Practitioners for whom CPD is not a requirement were excluded, i.e.: (i) those in non-clinical practice; (ii) those doing community service; and (iii) undergraduate students. At the time of the survey, there were 182152 practitioners who were eligible for participation.

An electronic questionnaire designed for self-administration and based on a survey of dentists ${ }^{[9]}$ was modified to reflect SA requirements and 
the range of health professionals registered with the HCPSA. Content and face validity were addressed through an iterative process of consulting with selected healthcare practitioners on the registers of different professional boards, members of the HPCSA's CPD committee, and by pilot testing. The 30 -item questionnaire covered practitioner demographics, as well as areas related to the study objectives: (i) patterns of CPD practice (i.e. methods of determining own learning needs, criteria for selection of CPD activities, preferred CPD learning activities); (ii) attitudes towards CPD; (iii) adherence to CPD requirements; (iv) facilitators and barriers to engaging with $\mathrm{CPD} ;(v)$ perceived impact of CPD; and (vi) implications for MoL. The questionnaire primarily comprised closed-ended questions suitable for ease of scoring and analysis in a large survey. Open-ended questions allowed for alternative responses.

Convenience sampling was used. In June and July 2014, practitioners who were registered with the HPCSA were invited to participate in the online survey (SurveyMonkey, USA) via the communication channels (e.g. websites, short message service (SMS) and email) of the HPCSA, professional associations and higher education institutions. Participants were given 2 weeks to respond and were sent reminders prior to the end of the data collection period. It was not possible to determine how many practitioners received the invitation to participate in the study. A total of 14572 questionnaires were received.

\section{Data management and analysis}

Data cleaning involved removal of 3257 incomplete questionnaires based on set criteria ( $<10$ of 30 questions answered and 8 duplicates) before exporting to Stata version 13.1 (StataCorp, USA) for analysis. Of the questionnaires included, not all respondents answered every question. Statistical analyses were performed using Pearson $\chi^{2}$ tests to determine associations between demographics and study variables (barriers, adherence with CPD requirements). A $p$-value of 0.05 was set for statistical significance. Answers to open-ended questions were analysed and no new response categories emerged.

\section{Ethical approval}

Ethical approval for the study was obtained from the University of Cape Town Faculty of Health Sciences Human Research Ethics Committee (ref. no. UCT FHS HREC 190/2013).

\section{Results}

Results are based on analysis of completed questionnaires by 11307 respondents, reflecting $6.2 \%$ of eligible practitioners. The distribution of respondents was relatively proportional to the registration of practitioners in the various boards, with the highest number of respondents (34\%) registered with the MDB (Fig. 1).

The majority ( $93.8 \% ; n=10093)$ of respondents worked in SA and were primarily from Gauteng (37.8\%), Western Cape (22.1\%) and KwaZuluNatal (14.2\%) provinces. Of the respondents, $73.8 \%$ were $<50$ years of age. Most (55.6\%) worked in the private sector, with $33.0 \%$ in the public service. Respondents (79.5\%) had a Bachelor degree (National Qualification Framework (NQF) level 7 or 8 ) as a minimum qualification. Table 1 shows selected demographic characteristics.

\section{Patterns of CPD practice}

Methods of determining learning needs

Most respondents (91.31\%; $n=11$ 124) reported being able to determine their learning needs. The most frequently reported methods used were self-assessment and audit of own practice (Fig. 2). Other approaches, while not currently used, were considered potentially useful.

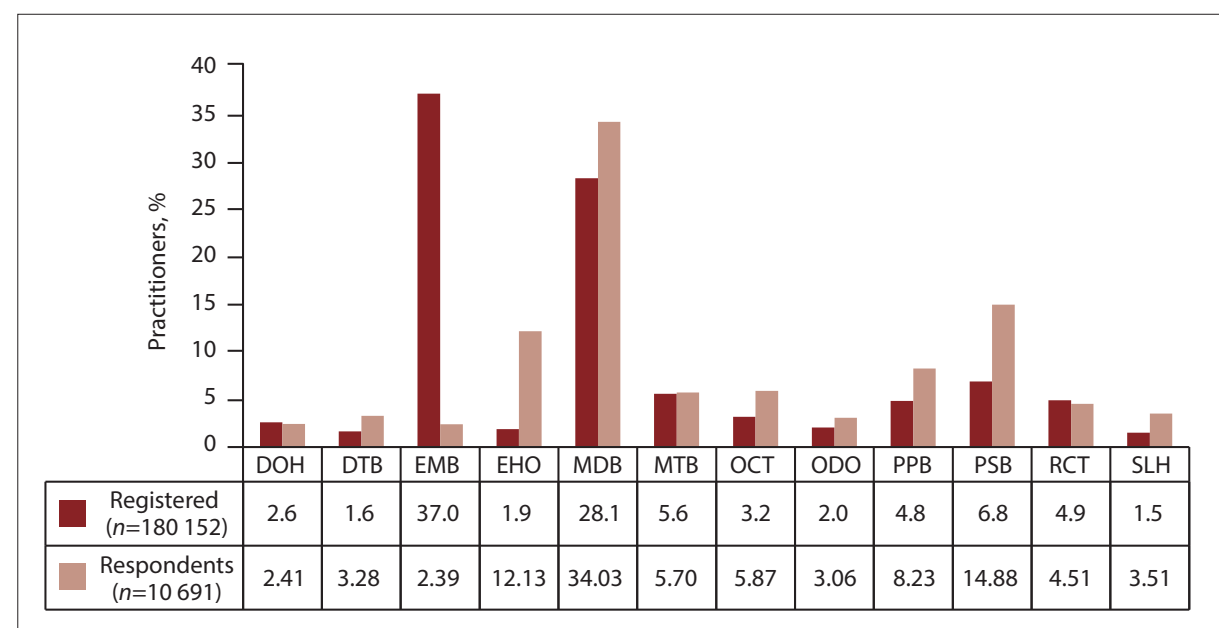

Fig. 1. Distribution of respondents across the various professional boards. $(D O H=$ Dental Therapy and Oral Hygiene; $D T B=$ Dietetics and Nutrition; $E M B=$ Emergency Care; $E H O=$ Environmental Health; $M D B=$ Medical and Dental; $M T B=$ Medical Technology; OCT = Occupational Therapy, Medical Orthotics Prosthetics and Arts Therapy; $O D O=$ Optometry and Dispensing Opticians; $P P B=$ Physiotherapy, Podiatry and Biokinetics; $P S B=$ Psychology; RCT = Radiography and Clinical Technology; SLH = Speech, Language and Hearing.)

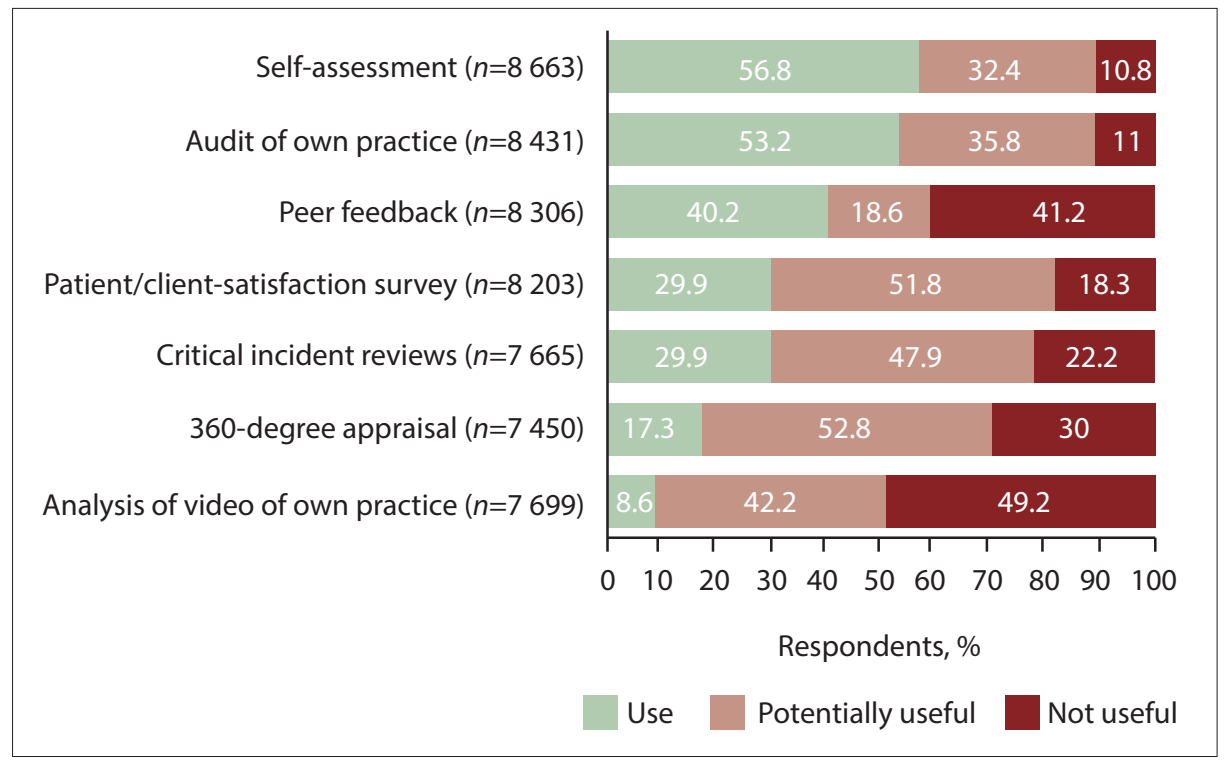

Fig. 2. Methods of determining learning needs. 


\section{Criteria for selection of CPD topics}

Respondents selected CPD topics based on their areas of interest $(80.2 \%)$ and expertise $(72.8 \%)$. Fewer respondents selected topics based on lack of expertise (64.6\%), knowledge gaps (66.1\%) and skills gaps (61.8\%), while $43.3 \%$ selected topics from a broad range.

\section{Nature of CPD learning activities}

Workshops, lectures and conferences (level 1 activities) were most frequently selected (Fig. 3). Clinical audit, publications, postgraduate study and videos with multiple-choice questions (MCQs) were less frequently chosen.

\begin{tabular}{ll}
\multicolumn{2}{l}{ Table 1. Demographic characteristics of survey respondents } \\
\hline Demographic characteristics & $\%$ \\
\hline Urban/rural work location ( $n=11$ 129) & $83 / 17$ \\
Female ( $n=11$ 194) & 59.9 \\
Age, years ( $n=11$ 129) & \\
$\leq 29$ & 20.0 \\
30 - 39 & 32.4 \\
40 - 49 & 21.4 \\
50 - 59 & 15.9 \\
60 - 65 & 5.6 \\
$>65$ & 4.7 \\
Member of a professional association ( $n=10$ 718) & 83.7 \\
Highest qualification obtained ( $n=11$ 165) & \\
Advanced/higher certificate (NQF 5) & 10.6 \\
Diploma (NQF 6) & 9.9 \\
Degree (NQF 7/8) & 37.4 \\
Postgraduate diploma (NQF 8) & 10.0 \\
Masters/specialist and subspecialist (NQF 9) & 28.1 \\
PhD (NQF 10) & 4.0 \\
NQF = National Qualifications Framework. &
\end{tabular}

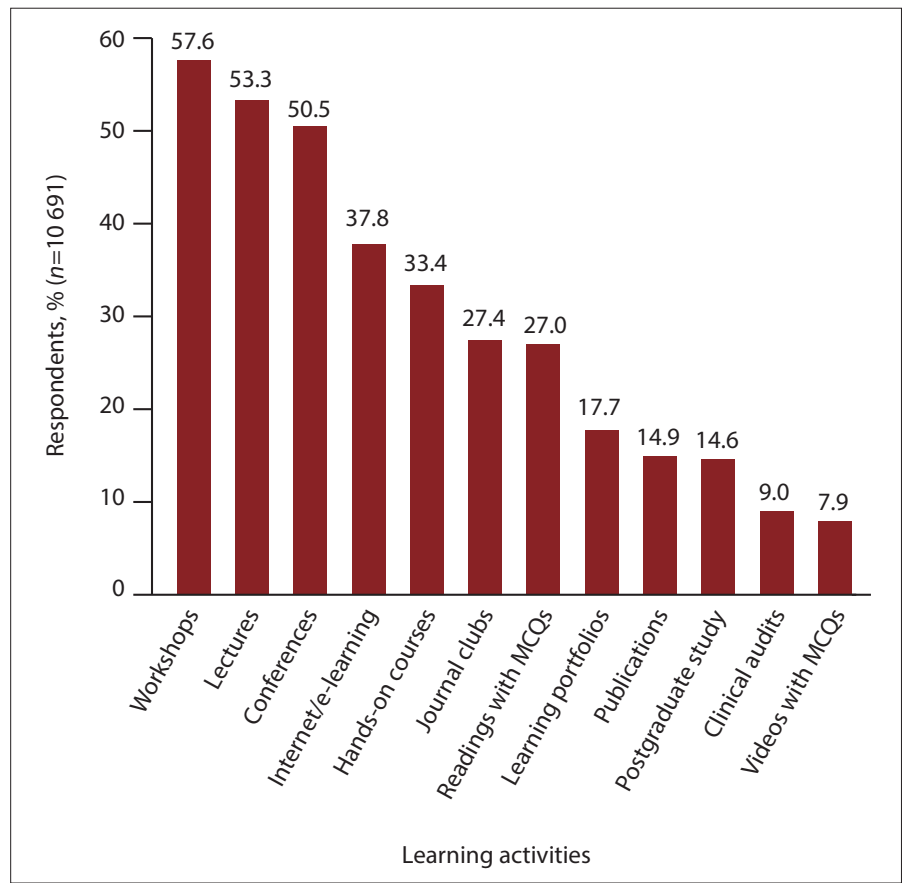

Fig. 3. Nature of continuing professional development learning activities selected. (MCQs = multiple-choice questions. $)$

\section{Self-reported adherence with CPD requirements}

Nationally, 47.6\% ( $n=10$ 995) of respondents had been selected for a CPD audit (an HPCSA administrative process that randomly selects practitioners and requires them to submit evidence of compliance with CPD requirements) during the previous 3 years, with $97.94 \%$ responding and $82 \%$ reporting adherence. For those working outside SA, $46 \%(n=595)$ were audited by the HPCSA and $92.5 \%$ were adherent. Generally, there were high levels of reported adherence with CPD requirements. Adherence was significantly associated with higher qualifications $\left(\chi^{2}(5, n=10313)=212.04\right.$; $p<0.001)$, membership of a professional association $\left(\chi^{2}(1, n=9956)=198.54\right.$; $p<0.001)$ and involvement of the employer (Table 2$)$.

\section{Attitude towards CPD}

Two-thirds (66.1\%; $n=10485)$ of respondents indicated that the number of CEUs expected was 'about right', while $30.6 \%$ felt that this requirement was too high. At least two-thirds (67.5\%) indicated that CPD had to be done because it is a statutory requirement, and $12.8 \%$ considered CPD to be a waste of time.

\section{Barriers to engaging with CPD}

Barriers to participating in CPD activities were reported by $55.8 \%$ ( $n=10093$ ) of respondents. The cost and location of CPD activities, loss of work days and difficulty getting time off work were primary barriers across several professional boards (Table 3). Cost as a barrier was reported by $>50 \%$ of respondents in 7 of the 12 professional boards, particularly by females $\left(\chi^{2}(1\right.$, $n=5910)=68.49 ; p<0.001)$ and rural respondents $\left(\chi^{2}(1, n=5890)=15.05\right.$; $p<0.001)$. A total of 575 respondents (5.7\%) were unsure of what is expected with regard to $\mathrm{CPD}$.

\section{CPD and the workplace}

The workplace supported CPD by offering learning activities ( $51.7 \%$; $n=9591)$ and by allowing time off work to engage with CPD (48.15\%; $n=11$ 160). Financial support from employers for CPD was more limited $(<31 \%)$. A quarter of respondents $(26.1 \% ; n=11066)$ indicated that their employers monitored adherence with CPD requirements.

\section{Perceived impact of CPD}

CPD was reported to have improved a broad range of areas (Fig. 4). While a high number of respondents (93\%) perceived that CPD resulted in an improvement in knowledge, there was a lower percentage of reports (68\%) of improvement in performance.

\section{Implications for maintenance of licensure}

Most respondents across professions (62.8\%; range $56.2-76.8 \%$; $n=10$ 615) supported an expanded CPD system for MoL, including continuing

\begin{tabular}{ll} 
Table 2. Employer support for CPD and reported adherence \\
\hline Employer support & Adherence \\
\hline Offers CPD activities & $\chi^{2}(1, n=8953)=130.41 ; p<0.001$ \\
$\begin{array}{l}\text { Financially supports CPD } \\
\text { Supports CPD related to }\end{array}$ & $\chi^{2}(1, n=7787)=113.21 ; p<0.001$ \\
practitioners' interest & $\chi^{2}(1, n=7646)=148.03 ; p<0.001$ \\
Allows time off for CPD & $\chi^{2}(1, n=8189)=54.22 ; p<0.001$ \\
Monitors adherence & $\chi^{2}(1, n=8083)=65.75 ; p<0.001$
\end{tabular}

$\mathrm{CPD}=$ continuing professional development 
Table 3. Barriers to participating in CPD across professional boards

\begin{tabular}{|c|c|c|c|c|c|c|c|c|c|c|c|c|c|}
\hline Barriers & $\%$ & DOH & DTB & EMB & EHO & MDB & MTB & OCP & ODO & PPB & PSB & RCT & SLH \\
\hline Boards, $n(N=10093)$ & & 237 & 338 & 1127 & 219 & 3508 & 556 & 615 & 311 & 843 & 1522 & 452 & 365 \\
\hline Cost & 45.5 & 51.1 & 51.2 & 32.5 & 56.6 & 34.9 & 32.4 & 74.8 & 39.9 & 63.4 & 53.6 & 48.5 & 67.4 \\
\hline Location & 38.6 & 46.4 & 44.4 & 35.3 & 40.6 & 31.6 & 34.4 & 61.1 & 37.6 & 43.4 & 39.0 & 44.0 & 55.3 \\
\hline Loss of workday & 29.2 & 27.9 & 27.2 & 19.6 & 12.3 & 27.6 & 15.7 & 44.1 & 26.7 & 39.6 & 35.2 & 22.8 & 43.6 \\
\hline Time off work & 23.6 & 19.8 & 23.1 & 25.7 & 22.4 & 23.5 & 29.1 & 25.5 & 17.4 & 18.7 & 21.6 & 34.5 & 20.6 \\
\hline Insufficient ethics activities & 16.4 & 11.0 & 29.6 & 17.9 & 25.1 & 15.4 & 21.4 & 22.8 & 13.2 & 13.6 & 10.8 & 21.5 & 15.1 \\
\hline Lack of employer support & 11.9 & 13.5 & 13.3 & 16.9 & 35.6 & 9.7 & 16.9 & 13.7 & 6.4 & 8.1 & 8.2 & 20.4 & 9.0 \\
\hline Obtaining CEUs from providers & 11.3 & 8.4 & 13.9 & 13.1 & 20.1 & 10.5 & 9.7 & 19.7 & 8.0 & 9.0 & 9.3 & 14.2 & 9.3 \\
\hline HPCSA support & 11.2 & 13.5 & 12.1 & 13.6 & 35.6 & 9.4 & 9.4 & 11.1 & 8.4 & 8.1 & 13.3 & 12.0 & 8.2 \\
\hline Quality of CPD activities & 8.4 & 11.0 & 9.2 & 8.4 & 14.2 & 8.0 & 6.5 & 9.3 & 6.1 & 10.0 & 10.4 & 10.2 & 8.2 \\
\hline Maintaining own CPD records & 8.4 & 8.4 & 14.8 & 7.4 & 5.5 & 8.0 & 9.4 & 10.2 & 10.0 & 7.8 & 8.8 & 8.2 & 6.3 \\
\hline Obtaining attendance records & 7.4 & 6.8 & 8.3 & 9.5 & 9.6 & 9.0 & 7.2 & 6.8 & 5.8 & 3.2 & 5.4 & 8.6 & 3.3 \\
\hline Unsure of CPD requirements & 5.7 & 5.9 & 5.3 & 9.6 & 11.0 & 4.6 & 7.2 & 4.7 & 4.5 & 3.4 & 6.7 & 7.1 & 1.9 \\
\hline
\end{tabular}

$\mathrm{CPD}=$ continuing professional development; $\mathrm{DOH}=$ Dental Therapy and Oral Hygiene; DTB $=$ Dietetics and Nutrition Board; EMB $=$ Emergency Care Board; EHO $=$ Environmental Health; $\mathrm{MDB}=\mathrm{Medical}$ and Dental Board; MTB = Medical Technology Board; OCP = Occupational Therapy, Medical Orthotics Prosthetics and Arts Therapy; ODO = Optometry and Dispensing Opticians; PPB = Physiotherapy,
Podiatry and Biokinetics; PSB = Psychology Board; RCT = Radiography and Clinical Technology; SLH = Speech, Language and Hearing; CEU = continuing education units; HPCSA = Health Professions Council of South Africa.

education ( $88.7 \%$; $n=10$ 193), with less support for those elements that entail assessment of performance and competence (Fig. 5).

\section{Discussion}

Respondents reflected a diverse group of practitioners across professions, age groups and qualifications and were primarily based in SA, females, in urban areas, $<50$ years of age, in the private sector and members of professional associations. The lower number of rural respondents may reflect the disparity in distribution of practitioners in urban and rural areas. $^{[10]}$

A range of strategies was used to determine learning needs, despite the absence of statutory guidelines, which is an improvement compared with earlier surveys. ${ }^{[11]}$ Some methods not currently used were considered to be potentially useful. Nevertheless, less than half supported the inclusion of assessments in MoL.

While this study did not explore the nature of self-assessments (the most popular strategy), subjective self-assessments may not be reliable, as practitioners' ability to accurately self-assess is limited, with the worst accuracy among those who were the least skilled and the most confident. ${ }^{[12]}$ There is consensus that there should be external assessment to evaluate practitioners' competence and performance and guide professional development. ${ }^{[12-14]}$ As the HPCSA develops MoL, it will be important for its professional boards to support practitioners by developing objective and externally verified tools for assessments.

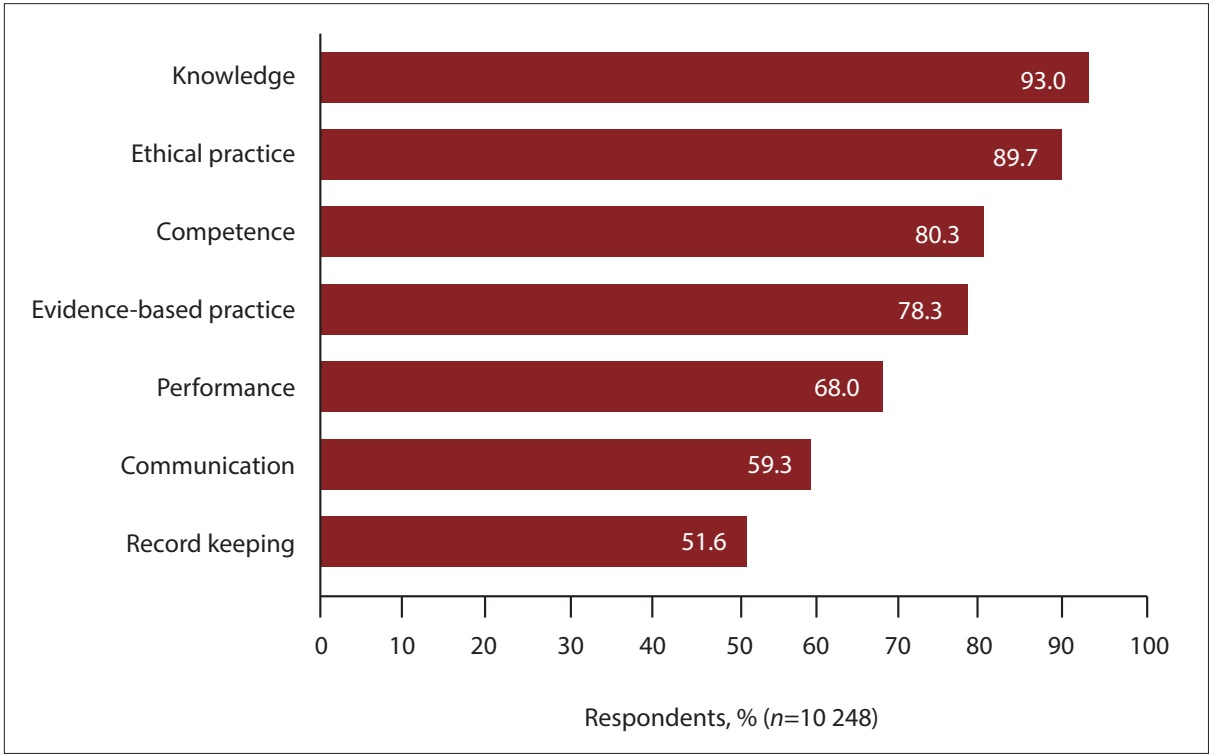

Fig. 4. Areas of practice reported to have improved with continuing professional development.

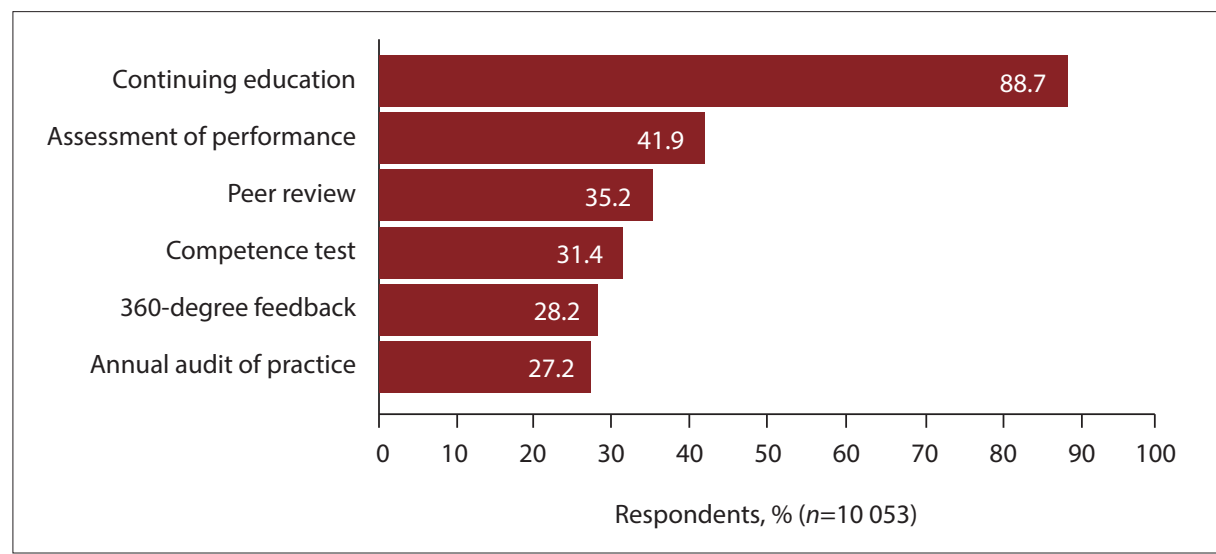

Fig. 5. Support for elements of an expanded continuing professional development programme for maintenance of licensure. 
Most respondents chose CPD activities related to their interest and expertise, with fewer selecting learning activities to address gaps in knowledge, skills and expertise. Practitioners often choose to participate in CPD activities within their comfort zone. ${ }^{[15]}$ Without guidelines and mechanisms to support the identification and selection of CPD learning activities that are appropriate and relevant to practice, it could be suggested that practitioners try to meet the CPD requirements by selecting learning activities in a manner described as opportunistic, erratic or casual. ${ }^{[16]}$ The impact of CPD activities is limited when undertaken in an ad hoc manner outside of a defined structure of directed learning and contributes little to improving practitioners' performance or patient/client health outcomes. ${ }^{[17]}$ Guidelines on how to develop learning plans that address gaps in knowledge and skills could be beneficial to practitioners in the context of MoL.

The most frequently chosen learning activities were input-based approaches (i.e. lectures, conferences and workshops), which are regarded as simple and cost effective and provide an easily quantifiable method of measuring individual CPD activity. ${ }^{[17]}$ Systematic reviews suggest that these common, primarily didactic learning activities have a limited effect on improving practitioner competence and performance, and no significant effect on patient and health systems outcomes. ${ }^{[17,18]} \mathrm{CPD}$ activities, which are interactive, provide opportunities to acquire and practice skills, ${ }^{[19]}$ involve multiple exposures, encourage reflection on practice, and are focused on outcomes, are reported as effective in improving practice and patient health outcomes. ${ }^{[17]}$

Respondents generally supported the expected level of engagement with $\mathrm{CPD}$, i.e. the number of CEUs expected annually. The finding that CPD had to be done because it is a statutory requirement, suggests that adherence may be related to the need to be compliant. A small but sizeable group (12.8\%) considered CPD to be a waste of time, suggesting a perceived lack of the inherent benefits of CPD. In comparison, only $0.4 \%$ of UK physicians surveyed indicated that CPD was unnecessary. ${ }^{[15]}$ Assisting practitioners to develop individualised CPD programmes that are linked explicitly to improving their professional performance and patient/client health, could result in greater ownership of professional development. ${ }^{[17]}$

Cost is a frequently reported barrier to CPD. ${ }^{[20-23]}$ Female and rural practitioners experienced cost as a greater challenge. Strategies to reduce costs should be explored, e.g. self-study activities ${ }^{[24]}$ aligned with identified learning needs. Challenges in accessing CPD activities due to the location in which they are offered, are common, ${ }^{[11,21,22]}$ as was time off from work to attend CPD activities. ${ }^{[21,22,25,26]} \mathrm{CPD}$ providers could be encouraged to make their offerings available through a variety of delivery modes, including online initiatives ${ }^{[24]}$ such as webinars and podcasts. Mechanisms to address the quality and relevance of learning activities, as well as administrative barriers that practitioners experience, need to be considered.

Workplace support for CPD in offering or allowing time off for CPD, was significantly associated with self-reported adherence. In SA, where CPD compliance is a statutory requirement for health practitioners, it is of concern that not all employers provide support. It is in the interest of employers and patients/clients that practitioners are up to date regarding professional knowledge and skills. ${ }^{[16,17]}$ Employers should be encouraged to support their practitioners' engagement with CPD.
$\mathrm{CPD}$ was perceived to improve knowledge more than performance. $\mathrm{CPD}$ activities are frequently not designed to promote clinical behaviour change, ${ }^{[27]}$ with delays of 5 - 50 years in the translation of acquired knowledge into practice. ${ }^{[17,28]}$ It is estimated that $30-40 \%$ of patients/clients do not receive care that is informed by best evidence, and $20-50 \%$ receive inappropriate care ${ }^{[17]} \mathrm{CPD}$ activities should increasingly be designed to meet the standard for improving practice and health outcomes.

There was support for an expanded CPD system for MoL to include continuing education activities, with much less support for other essential components of MoL, i.e. peer review, audit of practice and multisource feedback. Although respondents engage with such practices voluntarily, they are less supportive of these in a mandatory MoL environment, which could reflect perceived threats associated with review, assessments and meeting requirements for licensure in a formalised system. As these elements are part of the international components of MoL, work needs to be done to familiarise SA healthcare practitioners with requirements to move from the acquisition of knowledge to that of skills and improvement of performance.

\section{Study limitations}

Convenience sampling introduced bias. The results are based on a small sample of registered practitioners and exclude those without electronic access, leading to coverage bias. ${ }^{[29]}$ Selection bias is inherent to such a survey ${ }^{[30]}$ and could explain the high adherence. The results reflect the perceived impact of CPD and not the objectively measured impact. Practitioners' perceptions of whether they support the introduction of MoL and its implications were not explored.

\section{Conclusion}

Respondents to the online survey included 11307 health practitioners across all 12 HPCSA professional boards, with most being females, in urban areas, $<50$ years of age, in the private sector and in SA. Self-assessment, which has inherent limitations, was the most frequent method used to determine learning needs, with other approaches considered potentially useful. CPD topics were selected based on interest and expertise, with fewer topics related to lack of expertise and knowledge gaps. Workshops, lectures and conferences were the most popular CPD learning activities; these are known to have a limited effect on patient and health systems outcomes. Self-reported adherence was high and linked to membership of professional associations and involvement of the employer in supporting CPD. Employers should be encouraged to support their practitioners' engagement with CPD. Barriers included cost and location of CPD activities, and strategies to address these could include expanding the range of CPD activities to comprise self-study and online activities. In the transition to MoL, practitioners would need to be supported in determining their learning needs by devising and making available objective and valid assessment tools of competence and performance, such as 360-degree appraisals, peer review and online assessments of knowledge. Guidelines for learning plans should be developed to assist practitioners to tailor their programme of learning to address gaps and meet expected standards. Accreditation of $\mathrm{CPD}$ activities should require them to be interactive, provide opportunity to acquire and practise skills and be focused on improving performance and 
patient outcomes. Limitations of the study include the use of convenience sampling that probably led to bias, only the perceived impact of CPD could be described and support for the introduction of MoL was not explored.

\section{Declaration. None.}

Acknowledgements. The authors wish to acknowledge support of the HPCSA in recruiting practitioners for this study; Maxwell Chirehwa for his assistance with statistical analysis; Edelweiss Wentzel-Viljoen for initial discussions of the results and comments on a draft of the document; and colleagues who participated in the validation of the questionnaire.

Author contributions. SAS and TDF: substantial contribution to the conceptualisation and design of the study, analysis and interpretation of data, write-up of the article, and approval of the version to be published.

Funding. Statistical analysis was funded by Stellenbosch University.

Conflicts of interest. SAS was chair and TDF a member of the HPCSA's CPD committee at the time of the survey. Both authors are currently working on a MoL framework with the HPCSA.

1. De Villiers M. Global challenges in continuing professional development: The South African perspective. J Cont Educ Health Prof 2008;28(S1):25-26. https://doi.org/10.1002/chp.205

2. Van den Berg L, de Villiers MR. CPD - the learning preferences of general practitioners. S Afr Fam Pract 2003;45(3):10-12.

3. Health Professions Council South Africa. Continuing Professional Development. Guidelines for the Health Care Professionals. Pretoria: HPCSA, 2017. http://www.hpcsa.co.za (accessed 13 December 2017).

4. Rethans JJ, Norcini JJ, Baron-Maldonado M, et al. The relationship between competence and performance Implications for assessing practice performance. Med Educ 2002;36(10):901-909. https://doi.org/10.1046/j.13652923.2002.01316.x

5. Medical Council of New Zealand. Recertification and continuing professional development booklet. Wellington MCNZ, 2017. https://www.menz.org.nz (accessed 13 December 2017).

6. General Medical Council. The Good Medical Practice Framework for Appraisal and Revalidation. London GMC, 2013. https://www.gmc-uk.org/static/documents/content/The Good_medical practice_framework for appraisal_and_revalidation___DC5707.pdf (accessed 13 December 2017).

7. Federation of State Medical Boards. Maintenance of Licensure (MOL) Framework Policy. Washington: FSMB 2010. https://www.fsmb.org/ (accessed 4 November 2019).

8. In Practice. Recertification and professional development. Inpractice. 2017. https://www.inpractice.org.nz/guide/ welcome.aspx (accessed 13 December 2017).
9. Hopcraft MS, Manton DJ, Chong PL, et al. Participation in continuing professional development by dental practitioners in Victoria, Australia in 2007. Eur J Dent Educ 2010;14(4):227-234. https://doi.org/10.1111/j.16000579.2010.00615.x

10. Van Rensburg HC. South Africa’s protracted struggle for equal distribution and equitable access - still not there Hum Res Health 2014;12(1):26. https://doi.org/10.1186/1478-4491-12-26

11. De Villiers MR. The availability, utilisation and needs for continuing professional development of rural genera practitioners in the Western and Northern Cape. S Afr Fam Pract 2000;22(2):11-16.

12. Davis DA, Mazmanian PE, Fordis M, van Harrison RT, Thorpe KE, Perrier L. Accuracy of physician selfassessment compared with observed measures of competence: A systematic review. JAMA 2006;296(9):1094-1102. https://doi.org/10.1001/jama.296.9.1094

13. Chaudhry HJ, Cain FE, Staz ML, Talmage LA, Rhyne JA, Thomas JV. The evidence and rationale for maintenance of licensure. J Med Regul 2013;99:19-26. https://doi.org/10.7326/0003-4819-158-3-201302050-00022

14. Eva KW, Regehr G. 'Tll never play professional football' and other fallacies of self-assessment. J Cont Educ Health Prof 2008:28(1):14-19. https://doi.org/10.1002/chp.150

15. Schostak J, Davis M, Hanson J, et al. 'Effectiveness of continuing professional development' project: A summary of findings. Med Teach 2010;32(7):586-592.

16. Ahmed K, Wang TT, Ashrafian H, Layer GT, Darzi A, Athanasiou T. The effectiveness of continuing medical education for specialist recertification. Can Urol Ass J 2013;7(7-8):266. https://doi.org/10.5489/cuaj.378

17. Wallace S, May SA. Assessing and enhancing quality through outcomes-based continuing professional development (CPD): A review of current practice. Vet Rec 2016;179(20):515. https://doi.org/10.1136/vr.103862

18. Shibu L, Rajab E, Eldabi T. The role of social media in continuing professional development of physical therapists: A review of the literature. Physiotherapy 2015;101:e1384. https:// /doi.org/10.1016/j.physio.2015.03.1328

19. 2018 Annual Meeting of The Network: TUFH Abstract Submission Form. https://www.tfaforms.com/364076 (accessed 17 December 2017).

20. Cook DA, Price DW, Wittich CM, West CP, Blachman MI. Factors influencing physicians' selection of continuous professional development activities: A cross-specialty national survey. J Contin Educ Health Prof 2017;37(3):154-160. professional development activities: A cross-specisy
https://doi.org/10.1097/ceh. 0000000000000163

21. Dent AW, Asadpour A, Weiland T, Paltridge D. Australasian emergency physicians: A learning and education Dent AW, Asadpour A, Weiland TJ, Paltridge D. Australasian emergency physicians: A learning and educational
needs analysis. Part one: Background and methodology. Profile of FACEM. Emerg Med Australasia 2008:20(1):51-57. needs analysis. Part one: Background and meth D. A

22. Kanamu LG, van Dyk B, Chipeya L, Kilaha SN. Barriers to continuous professional development participation for radiographers in Kenya. Afr J Contin Educ Health Prof 2017;9(1):17-20. https://doi.org/10.7196/ajhpe.2017. for radio

23. Uarije C, Daniels ER, Kalondo L, Amkongo M, Damases-Kasi C, Nabasenja C. Radiographers' attitudes towards continuous professional development (CPD) at state hospitals in Windhoek, Namibia. S Afr Radiogr 2017;55(1):18-2 4. Lindsay E, Wooltorton E, Hendry P, Williams K, Wells G. Family physicians' continuing professional developmen activities: Urgent practices and potential for new options. Can Med Educ J 2016;7(1):e38.

25. Ikenwilo D, Skattun D. Perceived need and barriers to continuing professional development among doctors. Healt Policy 2014;117(2):195-202. https://doi.org/10.1016/j.healthpol.2014.04.006

26. Jiandani MM, Bogam R, Shah C, Prabhu S, Taksande B. Continuous professional development: Faculty views on need, impact and barriers. Natl J Integr Res Med 2015;7(2):43-75

27. Légaré F, Freitas A, Thompson-Leduc P, et al. The majority of accredited continuing professional developmen activities do not target clinical behavior change. Acad Med 2015;90(2):197-202. https://doi.org/10.1097/acm. 0000000000000543

28. Mickan S. Using Knowledge to Action Practice Change. Oxford: Centre for Evidence-Based Medicine, 2014

29. https://www.edrm.net/glossary/coverage-bias (accessed 18 October 2018)

30. Olsen R. Self-selection bias. In: Lavrakas P, ed. Encyclopedia of Survey Research Methods. Thousand Oaks, CA Sage, 2008:809-811. https://doi.org/10.4135/9781412963947.n52

Accepted 1 July 2019 